\title{
La utilització del folklore i la literatura popular per configurar l'ordre simbòlic de la mare i una escriptura femenina en la poesia de Maria Mercè Marçal
}

\author{
Montserrat Palau Vergés \\ Universitat Rovira i Virgili \\ montserrat.palau@urv.cat
}

RESUM

Ja des dels inicis de la seva trajectòria literària, el I977, una de les característiques destacades de la poesia de Maria Mercè Marçal (1952-1998) és la utilització de formes i motius del folklore i de la literatura popular. Aquest article analitza aquest ús, molt marcat en els primers llibres i també present en els posteriors, i explica com la literatura popular li servirà a l'autora per crear un món simbòlic de l'ordre de la mare, en contrast amb l'ordre patriarcal dominant també en la cultura i literatura. I, a més, per investigar i trobar la seva pròpia «escriptura femenina", d'acord amb les teories de les escoles feministes italianes i franceses dels anys setanta del segle XX.

PARAules Clau

poesia catalana; literatura popular; estudis de gènere; Maria Mercè Marçal

ABSTRACT

From the beginning of her literary career in 1977, one of the outstanding features of the poetry of Maria Mercè Marçal (I952-I998) was her use of forms and motifs from folklore and folk literature. This article analyses these aspects, which featured heavily in her early poetry but were also present in later work. It will explore how folk literature inspired her to create her own symbolic world governed by the figure of the mother, as opposed to the dominant patriarchal order existing in literature and culture. The article also traces the development of Marçal's writing in relation to the French and Italian theorists of "écriture feminine" in the I97os.

KEYWORDS

Catalan poetry; folk literature; genre studies; Maria Mercè Marçal

REBUT: 3O-O8-2OI7 | ACCEPTAT: I2-O9-2OI7 


\section{Retorn als orígens i recuperació d'una vena subterrània i femenina de la cultura ${ }^{1}$}

El I976, Maria Mercè Marçal guanya el premi Carles Riba amb el seu primer recull de poemes, Cau de llunes, que es publicaria l'any següent amb un notable ressò. El llibre s'estructura en quatre parts i, sobretot a l'última, hi trobem tot un seguit de poemes que connecten i es relacionen amb la literatura popular. Ran del premi i l'edició, Maria Mercè Marçal explicava, en una entrevista de Francesc Pané, quines havien estat les seves influències i, sobretot, la seva preocupació per investigar i recrear la literatura popular, com un retorn als orígens i a una vena subterrània i femenina de la cultura:

Especialment m'han estimulat Brossa, Foix, Salvat-Papasseit, Martí i Pol. M'ha preocupat especialment, potser sota la lluna de Blake, ${ }^{2}$ la recerca de la literatura popular (cançons de pandero, corrandes romanços, rondalles, etc.). En tot plegat entreveig un intent de retorn als orígens rurals, a la recuperació de la vena subterrània de la cultura, una contribució en molts casos femenina (en el bon sentit de la paraula) a la cultura (Pané I977: II).

L'any següent, en una altra entrevista, de Miquel Alzueta (I978), Marçal tornava a anomenar aquests autors - i hi afegia també Rosselló-Pòrcel, Estellés, Carner, Ausiàs March, Caterina Albert i Mercè Rodoreda- i repetia que una de les seves influències era «en un nivell molt més especial, la cançó popular tradicional.» I, sobre el seu segon llibre que aleshores escrivia, Bruixa de dol (I979), en aquest cas responent a Lluís Busquets (I979: 20), confessava que «persisteixo amb la cançó».

En els primers llibres de poemes de Maria Mercè Marçal, Cau de llunes (I977) i Bruixa de dol (I979), hi destaca amb força, doncs, el neopopularisme, és a dir, la reivindicació del folklore i de la literatura popular. Amb el Romanticisme i la Renaixença, la poesia catalana es va servir de les formes, els motius i els temes del folklore i la literatura popular. Aquest neopopularisme va ser també conreat, en les primeres dècades del segle $\mathrm{xx}$, per poetes noucentistes, avantguardistes i de la jove aleshores «generació del 36» o «generació de la República».3 Posteriorment, després de la Guerra, foren altres poetes que van utilitzar aquestes fórmules, com és el cas de Maria Mercè Marçal. Són molts els estudis dedicats a aquesta autora i, concretament, a la seva poesia. Però en tots es destaca aquesta influència i aquesta pràctica. Per exemple, Àlex Broch (2007: 329), per introduir la seva obra, resumeix de forma molt clara aquest aspecte quan parla de la poesia «neopopularista» de

I Aquest article s'emmarca en una línia de recerca sobre literatura popular catalana que ha rebut finançament del Ministeri d'Economia i Competitivitat a través del projecte d'R+D: FFI2015-64I28-P (MINECO/FEDER), i forma part de la investigació del Grup de Recerca Identitats en la Literatura Catalana (GRILC), consolidat per la Generalitat de Catalunya (2OI4 SGR 755).

2 Es refereix, sobretot, al recull Cançons d'innocència (1789) de William Blake. Llibres del Mall, col-lecció fundada per Maria Mercè Marçal, Ramon Pinyol Balasch, Gemma d'Armengol i Xavier Bru de Sala, havia publicat en català Cants d'innocència i d'experiència (1975). Com afirmava Jaume Pont (I989: 92), «Cau de llunes se'ns mostra com una obra concebuda des de l'hègira llunàtica de William Blake, de qui Maria-Mercè Marçal reconeix en una nota l'ascendent parcial de Cançons d'innocència».

3 En aquest sentit, cal esmentar un dels primers estudis catalans —i bàsic_- sobre el tema, el de Josep Romeu i Figueras, Poesia popular i literatura (I974). 
Marçal, que enllaça tant amb Lorca i Alberti com amb «Rosselló-Pòrcel, Sagarra, i els illencs de la generació dels 50», i que beu de les «fonts tradicionals -les corrandes, la cançó, el romanç— per acollir, també, un món de referència ple de ressons i mitologia popular». Les connexions de la poesia de Marçal amb la de García Lorca també les ha analitzat Laia Climent (2004: 335-345). I, encara, en aquesta línia de connexions i influències sobre les formes de la poesia popular, ens faltaria afegir-hi Joan Brossa, amb qui Marçal compartia amistat (Bordons 20IO: I27-I28), i, a més, Clementina Arderiu, de qui, en les seves recerques de les genealogies femenines i les «mares literàries», va prologar i editar una antologia poètica (Arderiu 2008) i sobre la qual va publicar també diversos estudis (Ibarz 2004). Una anàlisi exhaustiva que també recull, des de diverses òptiques i apartats, la utilització de la literatura popular en la poesia de Maria Mercè Marçal és la tesi doctoral de Caterina Riba (2OI2) i altres publicacions seves que n'han sorgit (20I4).4

En els primers llibres de poemes, Maria Mercè Marçal se serveix del folklore i de la tradició oral i popular, tant pel que fa a formes com a motius. En els dos primers llibres, com hem comentat, són nombroses les formes neopopularistes, combinades amb d'altres de cultes, i, amb el temps, en les obres posteriors, aquestes darreres s'imposaran, tot i que, de forma escadussera, també hi trobarem metres populars. En la seva poètica, són diversos els poemes que segueixen els metres i les retòriques populars. Ens trobem amb moltes cançons, corrandes i romanços, així com amb versos heptasíl.labs i repeticions de ritme i rima, paral-lelismes o la inclusió, també, de refranys o onomatopeies.

Podem esmentar, entre d'altres, les «Cançons de paper fi» o les «Corrandes de lluna» en Cau de llunes (I977); «Cançó de saltar a corda», «Cançó de fer camí» o «Velles corrandes per a la Pepa» en Bruixa de dol (I979), o, també, «Cançó de bressol» i «Romanç de la solitud sense sabates» en Sal oberta (I982) o «Cançoneta lleu» en Desglaç (I988). Serveixin com a exemple les «Corrandes de lluna»:

Avui, si venia

la lluna morta,

l'amor cantaria

que truca a la porta.

I si ens arribava

amb gep a Ponent,

l'amor cantaria

en quart creixent.

Si la lluna era

rodona i roja,

l'amor cantaria,

l'amor boja.

4 Totes les obres i publicacions de i sobre Maria Mercè Marçal estan inventariades i són consultables a l'Arxiu de la Fundació Maria Mercè Marçal. Accessible en línia: <http://www. fmmm.cat/autora.html> [data de consulta: agost de 20I7]. 
Mes ai, si ve blanca

rodona i blanca,

l'amor cantaria

que la porta tanca.

I si duu la lluna

un gep a Llevant,

l'amor cantaria

l'amor minvant (Marçal I989: 62).

En aquestes «Corrandes de lluna», Marçal, a més, fa tot un joc simbòlic a partir de la cançó popular de «La lluna, la pruna» i, alhora, les bruixes. I és que, a més de les formes mètriques pròpies d'aquesta literatura, la presència de motius de la tradició oral i popular també la trobem en d'altres creacions i altres formes de versificació (sonets, suites, sextines). ${ }^{5}$ Com els jocs i l'oralitat infantil, les festes populars o el motiu esmentat de la bruixa. Referències a jocs i expressions infantils, com «ralet, ralet», «saltar a corda», «conillets a amagar», jugar a pilota o «fer la rateta». O poemes com «Endevina, endevinalla» (Marçal I989: 22I) que, a partir d'un conjunt de quatre interrogacions, arribem a la resposta. No és estrany, doncs, que, fins i tot, hi hagi edicions i antologies per a un públic lector infantil i juvenil de la poesia de Maria Mercè Marçal (2004a, 2004b i 20I5) i estudis sobre aquestes (Selfa 2OI5). Serveixin en aquest cas com a exemples la «Cançó de saltar a corda» $\mathbf{i}$ «Tríptic per a una quimera»:

\section{CANÇÓ DE SALTAR A CORDA}

La pluja és una bruixa

amb els cabells molt llargs.

Cascavells li repiquen

tota la trena avall.

A la nit, si venia,

ho fa sense avisar,

estalzim a la cara

i el vestit estripat.

Si fa córrer l'escombra

conillets, a amagar!

amagats que seríem

que no ens atraparà.

Darrere la cortina

fem-li adéu amb la mà (Marçal I989: I73).

5 Vegeu l'anàlisi d'alguns poemes de la suite de sonets feta per Josep Bargalló (20I2). 
La utilització del folklore i la literatura popular per configurar l'ordre simbòlic...

TRÍPTIC PER A UNA QUIMERA

Ralet, ralet... Paraules petitones.

Zapz? La Maiameixé t'eztima finz al cel!

Besar-te els ulls és fer volar un estel

en un bosc sense llops ni destrals. Te n'adones?

Cuca de fanalet, al ràfec de l'orella

hi he arribat amb l'amor humit de serení.

Penyora aquest joc, duré, demà al matí,

braçalets de petons a cada manuquella.

Cerquem tresors menuts, amagats endebades.

I què, si ens hi perdíem per set anys teraranys!

Per obrir la magrana tancada sense panys

ens hem calçat als dits els peücs de les fades.

I hem alçat, a l'esqueix de l'hora violeta,

una festa d'olors amb la trena desfeta (Marçal I989: I64).

També cal esmentar les referències a les festes populars. La secció «Estrelles altes, veles baixes» del seu primer poemari, Cau de llunes, encapçalada, a més per un fragment de la cançó popular «A la vora del riu, mare, / m'he deixat les espardenyes» i per una citació d'un poema de Vicent Andrés Estellés, en què parla de les festes de Moros i Cristians d'Alcoi, està dedicada a les festes populars. El primer poema està dedicat a la festa de sant Joan, «Matinet de sant Joan, les herbes tenen virtut» (Marçal I989: 60). I el darrer, que comença amb presagis i creences, acaba també en una festa a la plaça:

...mentre músics antics
engeguin la sardana,
polques i rigodons
i el ball de l'almorratxa,
i tots saltin de ple
la foguera Joana... (Marçal I989: 77).

I, sobretot, les bruixes. Podríem esmentar també les sirenes com a motiu recurrent, però en aquest cas la poeta no es remet a la mitologia popular i el folklore de sirenes o dones d'aigua, sinó a les de L'Odissea. I, encara, la figura del drac, que li serveix com a desconstrucció per a les seves teories feministes. ${ }^{6}$ En aquesta línia

6 Ho explicava Marçal en el pregó que va fer com a guanyadora del premi Crexells el dia de sant Jordi de 1996 a l'Ateneu de Barcelona: «El drac és, per a mi, la imatge de tot allò que és exclòs, i allò que és exclòs retorna en forma d'amenaça, de força obscura, d'enemic. Tot procés civilitzador exclou i limita el seu domini sobre la natura, i sobre les més diverses facetes 
s'inclouen les bruixes, que li valen com a estereotips que manipula. El títol del seu segon llibre de poemes, Bruixa de dol, 7 ja és ben explícit amb el joc que ens remet tant a les bruixes com a la cançó de la lluna vestida de dol, que, alhora, és un homenatge al recull de sonets de J.V. Foix, Sol, i de dol.

Les bruixes són les dones que no acceptaven l'ordre i la tutela dels homes i, d'aquí, la seva caracterització gairebé sempre en negatiu -lletges, deformades, amb berrugues, dolentes... Les bruixes de Marçal són, en canvi, les dones indòcils i rebels que no volen subordinar-se. ${ }^{8}$ En els seus poemes manté la imatgeria que popularment les caracteritza — escombra, cabellera, danses sota la lluna... —, però canvia la mirada que habitualment es projecta sobre elles:

\author{
Magdalena, \\ lluna plena, \\ qui t'ha fet \\ lo mal del peu? \\ Corre, lluna, \\ que t'empaita \\ la guineu! \\ Magdalena, \\ lluna plena, \\ on has perdut \\ lo didal? \\ ai, quan brodis \\ boires baixes \\ amb l'agulla \\ et faràs sang!
}

de l'experiència, el seu control sobre els impulsos primaris de vida i de mort comporta l'exili més enllà de la consciència i del llenguatge d'allò que és negat, i implica, per tant, sofriment soterrat, passió. I tot allò que queda fora, irreductiblement altre i desconegut, és associat a les forces del mal. El drac és el poder terrible d'allò que en nosaltres resta del que queda exclòs. [...] Si com a escriptora sento que les meves arrels s'enfondeixen en la sang del drac, com a dona no puc oblidar que el femení, més enllà de la pobra representació de la donzella salvada per l'heroi, ha quedat exclòs històricament de la nostra civilització i es troba, també, a la banda del monstre» (Marçal I996: I4-I5).

7 Cal esmentar el monogràfic d'estudis sobre el llibre Bruixa de dol, coordinat per Fabrice Corrons i Sandrine Frayssinhes Ribes (2012), amb articles de Sandrine Frayssinhes, Agnès Toda i Bonet, Lluïsa Julià, Neus Aguado, Laia Climent, Caterina Riba, Anna Esteve, Maria Antònia Massanet, Fina Llorca, M. Àngels Francès, Mercè Ibarz i Merri Torras.

8 Com assenyala Josep-Anton Fernàndez (2004: 206), la bruixa, com a dona immoral, «que desitja i està en control del seu cos» és una de les imatges prominents: «És la imatge més potent de la dona com a diferència, monstruositat i misteri. La bruixa està de dol a causa d'una dolorosa herència d'opressió que constitueix una ferida oberta i reoberta cada dia per la fragilitat de la identitat femenina reiterada en l'experiència d'amor i desamor que caracteritza l'obra de Marçal». 
La utilització del folklore i la literatura popular per configurar l'ordre simbòlic...

Magdalena,

lluna plena,

vora mar

perds los esclops,

quan t'afues

matinera

amb l'onada

a retaló.

Magdalena,

lluna plena,

tens l'escombra

al cap del llit,

per fugir-hi

en la ventada

sota l'ombra

de la nit.

Magdalena,

lluna plena,

cabellera

fins al peu.

Corre, lluna,

que t'atrapa

la guineu!

Magdalena,

lluna plena,

duus estels

al davantal

i els escampes

fora vila

lluny de casa

i de l'hostal.

Magdalena,

lluna plena,

no perdis

lo mocador:

fes adéu 

a la masia.
Corre, lluna,
amb l'onada
a retaló! (Marçal I989: I44-I46).

Maria Mercè Marçal recorre als orígens amb el món infantil i el llegat de la mare de cançons, paraules i contes. Les seves bruixes, en positiu, són les predecessores de les feministes i de la sororitat femenina i se serveix de «la tàctica de la inversió simbòlica» (Riba 2OI2: I47). Marçal vol canviar els tòpics i l'imaginari i, per això, també trenca amb els elements binaris, com l'afirmació dels dos models de dona, el de la bondat i la submissió, lligat a la verge Maria i les fades dels contes, i el del pecat i la transgressió, lligat a Eva i les bruixes. Així, si en la cultura popular les bruixes són les contràries a les fades, en la poesia de Marçal, bruixes i fades són companyes. Bruixes i fades s'estimen perquè tenen, en definitiva, la mateixa condició i els mateixos objectius: ${ }^{9}$

\section{AVUI LES FADES I BRUIXES S'ESTIMEN}

Avui, sabeu? les fades i les bruixes s'estimen.

Han canviat entre elles escombres i varetes.

I amb cucurull de nit i tarot de poetes

endevinen l'enllà, on les ombres s'animen.

És que han begut de l'aigua de la Font dels Lilàs

i han parlat amb la terra, baixet, arran d'orella.

Han ofert al no-res foc de cera d'abella

i han aviat libèl-lules per desxifrar-ne el traç.

Davallen a la plaça en revessa processó, com la serp cargolada entorn de la pomera, i enceten una dansa, de punta i de taló.

Jo, que aguaito de lluny la roda fetillera, esbalaïda veig que vénen cap a mi

i em criden perquè hi entri. Ullpresa, els dic que sí (Marçal I989: I35).

Segons Mercè Otero (20IO: 8I-83), aquest poema defineix l'univers poètic en femení de Maria Mercè Marçal perquè hi apareixen, «de forma harmònica i ordenada", "tots els elements que construiran la tradició feminista en la seva forma més genuïna» i, així, la figura de la bruixa, que forma part de la tradició popular i les cançons infantils, és utilitzada no només com a recuperació del passat, sinó per «construir una tradició pròpia amb objectius feministes». Tornem al títol

\footnotetext{
9 Aquesta transgressió de Marçal de transmutar en positiu i en sororitat bruixes i fades, la trobem també en un conte feminista dels darrers anys, que ha tingut molt de recorregut i ressò, sobre la Ventafocs, La Cenicienta que no quería comer perdices (López i Cameros 2004), en què se subverteix la figura de la fada.
} 
d'aquest primer apartat per donar pas al segon: la vena subterrània i femenina per crear un ordre simbòlic i experimentar en la recerca d'una escriptura femenina. També, com a recerca identitària, en què vida i cos s'entrellacen, mirall una de l'altre en tota la seva trajectòria (Julià 20I7).

\title{
2. Escriptura femenina i configuració de l'ordre simbòlic de la mare
}

Maria Mercè Marçal, quan, en una entrevista, Marta Nadal (I989: I84-I88) li preguntava sobre la figura de les bruixes, oposades a l'imperi de la raó masculí, responia que, si bé la raó ha estat identificada històricament de forma patriarcal amb l'imperi del fal·lus, ella no volia mantenir aquest tòpic amb dones que es movien en terrenys irracionals:

Si el femení ha estat associat a la bruixa, jo he partit d'aquest fet; però no estic d'acord que la cremin i per això la reivindico. Em penso que, tot i que a la llarga s'haurien de qüestionar tots aquests paràmetres, a mi, com a punt de partida, m'han servit. D'alguna manera, dient que les fades i les bruixes s'estimen trenco aquesta tradició.

Marçal acaba amb aquesta tradició i no fa distinció entre dones bones-fades i dones dolentes-bruixes. S'imposa la sororitat i no l'estereotip androcèntric de les dones barallades o oponents entre elles. Han begut, totes i juntes, de la «font del Lilàs» i el feminisme violeta les fa dansar i vèncer. És la rebel-lió d'un aquelarre de bruixes i fades, amb la lluna, l'aigua i les herbes fetilleres, i, com diu el títol d'una de les seccions de Bruixa de dol, «sense llops ni destrals», sense caputxetes devorades o enganyades, sinó en un altre escenari simbòlic. I, així, també s'inscriu, per extensió, en l'ordre de la mare, en la ginocrítica i les genealogies femenines, tal com havia teoritzat Luisa Muraro en L'ordre simbòlic de la mare (I995), sobre el paper de la mare com a transmissora del llenguatge i de la interpretació simbòlica de part de la realitat (Climent 2002: 73-78).

En el seu primer poemari, Cau de llunes, Marçal ja ens anuncia que ve carregada de «cançons de paper fi», de llunes i arracades:

\author{
Cançons de paper fi \\ m'omplen la sàrria \\ i em foraden el fons \\ de la butxaca. \\ Mireu quin caramull \\ de llunes blanques! \\ Duc llunes i cançons \\ per arracades (Marçal I989: 57).
}

Cançons i llunes per arracades, dues apreciacions gens banals, en el sentit que Maria Mercè Marçal se serveix del folklore i l'oralitat també amb un objectiu concret, el d'articular un discurs sexuat en femení per abastar aquest ordre simbòlic de la mare. I, per tant, com comenta Anna Montero, recorre a una mitologia i un llenguatge matriarcal: 
Entre el silenci i el xiscle, ella intenta un altre camí, tracta de recuperar la llengua poètica d'abans del patriarcat, cerca els elements de la llengua abolida. Per fer-ho, recorre als signes d'una mitologia matriarcal, apel-la al llenguatge poètic que, segons l'escriptor Robert Graves, seguia les normes de «la Triple Musa», encarnació de la Deessa Blanca que regeix «la vertadera poesia», la poesia que es practicava en la societat preapol-línia. En aquest sentit s'ha d'entendre la utilització de Maria-Mercè Marçal, en els primers poemaris, dels ritmes i expressions populars (que ella atribuïa, en el seu cas, a la influència materna, relacionada amb la Natura, enfront de la paterna, marcada per la Cultura), així com la presència d'elements —plantes, personatges, símbols_ - i espais que remeten al món rural, agrícola, regit per la successió de les estacions i de les llunes, sota el signe de la deessa de la terra (2008: 233).

Per això, a partir de la seva maternitat, Marçal vol establir també un diàleg poètic amb la seva filla des de signes propis i llibertat: «I hi cerco signes, alfabets d'arrels / per confegir-te un nom que no t'escanyi. / Per bastir-te una casa que no et segui / veles ni rems» (Marçal I989: 265).

Maria Mercè Marçal coneixia i seguia —entre d'altres- les teories del feminisme de la diferència, tant el francès com l'italià (Climent 2003: 88-99; Díaz 20I4). ${ }^{\text {Io }}$ Les teòriques franceses -Luce Irigaray, Julia Kristeva o Hélene Cixous- partien de l'afirmació que les estructures del coneixement estan codificades en el llenguatge. Des del desconstructivisme de Derrida i el psicoanalisme de Lacan, les teòriques d'aquesta escola afirmen que els sistemes de llenguatge són sistemes de poder, i, a més, construccions de poder amb contradiccions internes que han de ser apartades, és a dir, reconstruïdes a part. Focalitzant en el llenguatge, particularment en l'adquisició de llenguatge en la infantesa, aquesta escola crítica francesa intenta desconstruir els discursos patriarcals. Si Simone de Beauvoir parlava de les dones com «l'altra», aquestes feministes creuen que el llenguatge femení està reprimit, que és «l'altre» en l'àmbit social i cultural. Segons els seus postulats, la crítica literària tradicional ha convertit la literatura en una institució regulada per gèneres, cànons i històries, per la qual cosa escriure i escriptura es defineixen per la seva pràctica i pel seu passat (Carbonell 2004: 3I-42). Marçal s'inscriu en el tractament del llenguatge i del parlar no neutre d'Irigaray i de la recerca, com Cixous (I995), d'una escriptura femenina. Luce Irigaray (I974, I979 i I985), anant més enllà dels filòsofs descontructivistes, afirmava que el pensament d'occident està format per un imaginari que té la morfologia del cos masculí, per la qual cosa, doncs, les teoritzacions i les abstraccions estan també modulades des d'aquest cos. Per tant, l'ordre simbòlic patriarcal exclou tot allò femení. I el que cal, com

Io Cal esmentar, en aquest sentit, la sèrie d'articles des de la perspectiva de gènere sobre l'obra de Maria Mercè Marçal editats per Fabrice Corrons \& Sandrine Frayssinhes Ribes (20II). També, anteriorment, cal referir-se al dossier que li va dedicar la revista Lectora (Segarra 2004) amb articles de Marta Segarra, Lluïsa Julià, Rosa Cabré, Joana Sabadell-Nieto, Josep-Anton Fernàndez, Fina Llorca, Kathleen McNerney, Rosa Rius, Carme Riera i Anna Montero. I no podem oblidar el monogràfic de la revista Reduccions. Revista de Poesia (2008: 87-298), amb articles de Josep Maria Sala Valldaura, Lluís Calvo, Susanna Rafart, Rosa Delor, Pilar Godayol, Dolors Udina, Francesc Codina, Anna Montero, Laura Borràs, Joan Elies Adell, Marie-Claire Zimmermann i Laia Climent. 
Marçal investiga, és la possibilitat de construir un imaginari a partir del cos i la sexualitat femenines.

Aleshores, dins d'aquests paràmetres, aquestes autores es plantegen com qüestionar la relació entre llenguatge femení i literatura sense desconstruir-ne els valors històrics, tenint en compte que el llenguatge ha estat el mecanisme central pel qual els homes s'han apropiat del món. Les formes lingüístiques amb què els homes han colonitzat les dones, argumenten, són amb les que els homes han devaluat la sensualitat a favor del simbolisme. Així, una de les seves línies de recerca fou les representacions alternatives que poden ser construïdes. Perquè, si la literatura és el centre, si la literatura sovint representa els somnis i l'inconscient, si la literatura és acumulació de subjectivitat i les formes discursives literàries ens proveeixen d'espais i d'absències (o moments), també cal cercar quines altres formes de subjectivitat poden ser representades. I, sobretot, com representar i expressar la subjectivitat femenina quan no hi ha un llenguatge literari que no estigui marcat per la tradició del patriarcat. Luce Irigaray - a qui Marçal va esmentar reiteradament en els seus assaigs - oposa, a la idea humanista d'un subjecte universal asexuat, una subjectivitat mítica femenina, que comporta també la creació d'un vocabulari nou, d'una nova imatgeria femenina, de nous símbols i metàfores sobre la feminitat i el cos de les dones. Marçal coneixia bé aquestes teories i, en una entrevista que li va fer Anna Montero per a la revista Daina el I986, es va referir al fal-logocentrisme, el terme de Derrida per qualificar el discurs hegemònic centrat en la raó (logos), però també en el masculí (fal·lus):

La cultura, oposada a la natura, i tota aquesta tradició racionalista, està força en crisi des de diversos punts. No sé si el feminisme hi ha contribuït o hi ha coincidit, és difícil de saber quin és el desencadenant. Com a mínim, té molt a veure amb aquesta crisi d'una certa imatge del jo racionalista. Com a mínim, és un dels moviments que qüestiona aquest fal·logocentrisme. (Montero 2004: 274). ${ }^{\text {II }}$

El problema principal de les autores ha estat l'expressió del seu ordre simbòlic femení a partir d'uns codis i un imaginari masculí. En aquest aspecte, cal tornar a esmentar les feministes italianes de la diferència i, en concret, de nou, l'obra de Luisa Muraro, L'ordre simbòlic de la mare (I995), en què teoritza que el món veritable és aquell que es dóna en la nostra experiència a través de la paraula i la paraula a través de l'experiència. I, per tant, «cal recuperar el punt de vista dels orígens, quan el món naixia amb nosaltres i amb el nostre saber parlar» (I995: 80). Així, doncs, cal recuperar el món de la mare. Entrar en l'imaginari el llenguatge masculí, l'ordre del pare, sense voler renunciar, ans el contrari, a l'ordre de la mare.

II Anys abans, quan al gener de I995 Maria Mercè Marçal, en la campanya de la Conselleria de Cultura de la Generalitat de Catalunya, fou «escriptora del mes», en el llibret que es va editar per aquest motiu, Anna Montero ja remarcava l'empeny i els treballs de la poeta per recuperar i reivindicar aquesta «cultura femenina» i les genealogies: «És aquesta preocupació per integrar la veu femenina al món de la cultura el que l'empeny, d'una banda, a revisar les escriptores més clàssiques, tot descobrint-hi accents de rebel-lió i malestar on tradicionalment només es llegia conformisme i submissió; d'una altra banda, l'empany a traduir autores que 'normalment' haurien d'esperar el seu torn, després dels escriptors, és clar. Pensem en l'antologia de poemes de Clementina Arderiu, Contraclaror, com també en les traduccions de Colette, Yourcenar, Akhmatova i Tsvetàieva» (Montero I995: 9). 
L'oposició, com explicava Marçal, entre la Cultura —-masculina-, creada contra la Natura -femenina-:

Penso que som en una tradició en què la identitat i la idea de subjecte van molt lligades a un determinat concepte d'identitat i de subjecte que, precisament, exclou les dones. Dins aquesta tradició, té una identitat qui fa la cultura, i la cultura s'oposa a la natura, representada per la dona. El problema, per a les dones, és com trobes una identitat en tot aquest embolic. Una forma, la més fácil (?), d'adquirir una identitat és prescindir d'aquest grup al qual pertanys per naixement, i aquest pas es pot reflectir molts cops per un rebuig de la maternitat (perquè la imatge de la dona associada a la natura està condicionada pel tema de la maternitat, no només per com les dones veuen la maternitat, sinó per com els homes viuen el fet d'haver nascut d'una dona). No és el meu cas; el problema es planteja quan tu vols actuar com a subjecte, com a algú que té identitat, però sense abandonar aquest grup i penses que el que cal és un marc, un àmbit on es pugui ser dona, sense renunciar a ser natura ni a fer cultura (Sabadell I998: 20).

Per això, seguint en aquesta línia de la Cultura, ordre del pare com Atenea, i la Natura, ordre de la mare, com la Medusa, Maria Mercè Marçal afirmava en un congrés del I994 que les escriptores — concretament les poetes- són alhora Atenea i Medusa. És a dir, les creadores són com Atenea, que va sortir del cap de Zeus, són filles del Pare, de les seves lleis i la seva Cultura — «el gran pacte masculí contra Natura»-, i d'un pare, a més, que ha invisibilitzat la força femenina. Però les creadores també són Medusa, són la dona monstre, el femení indomat, salvatge i nua en el mirall. Diu Marçal que les creadores són:

Pensant-ho bé, però, la dona escriptora i singularment la dona poeta - filla també sense mare, com he dit, en el terreny cultural— no és mai del tot aquesta guardiana modèlica de l'ordre patern que Atenea pot simbolitzar. Més aviat se situaria a mig camí, sempre en un espai híbrid entre Atenea i la Medusa, excavant túnels subterranis entre una i altra, sense ser capaç de triar entre totes dues encara que una o altra pugui predominar. Movent-se entre la Llei del pare que organitza el món tot excloent-la o inferioritzant-la en tant que dona, i el femení inarticulat, caòtic, l'inexistent ordre simbòlic de la mare (Marçal I997: I80).

Per equilibrar aquestes dues forces creatives, Marçal se servirà del llenguatge: «Tot es troba en el llenguatge. Fins i tot en el cas d'haver d'inventar, hauràs d'inventar a partir d'alguna cosa. No es pot decidir: a partir d'ara tabula rasa; fem un llenguatge femení» (Sabadell I998: I8).

I per recrear aquest «inexistent ordre simbòlic de la mare» utilitzarà la literatura oral. L'oralitat i el món d'infantesa seran la forma de recuperar la figura materna, la que la va portar també al coneixement d'una cultura específica, diferent a l'apresa del pare:

Sempre havia pensat que l'accés a la cultura, a la cultura escrita, m'havia vingut del pare, que dins de la família era el que portava llibres, etc. Però en un moment determinat em vaig adonar que hi havia un element previ, que és aquest substrat de poesia popular, amb el qual es relaciona tant la meva poesia, i que estava vinculat a la mare. És per això que per a mi la 
poesia popular és, en part, una mena de placenta que em dóna seguretat (Sabadell I998: I7). ${ }^{\mathrm{I2}}$

Dolors Sistac (2000: III-II5) assenyala tres «baules», tres constants en la poesia de Marçal: l'enllaç a una tradició poètica femenina, la connexió a fonts populars i de memòria col-lectiva, i el que l'autora anomena «Baula d'un paisatge femení». Caterina Riba, per la seva banda, assenyala que Marçal, seguint les teories d'Irigaray, que no creia, com deia Freud (Tòtem i tabú), que la nostra societat fou fundada sobre un parricidi, sinó sobre un matricidi, i que pensava que la relació mare i filla sempre havia estat negada dins la societat patriarcal, se serveix de la incorporació de la tradició oral «per recuperar la figura materna»:

En l'obra de Marçal el lligam amb la mare es manifesta de forma latent a través de les estrofes i cançons procedents de la cultura popular que recuperen d'alguna manera l'experiència amniòtica, el punt àlgid de la relació mare-filla. La poesia marçaliana recobra la tradició oral, les cançons i les festes populars, per tal de reivindicar l'espai matricial, vinculat al femení, menystingut en la tradició occidental. El retorn als orígens en la poesia de Marçal engloba la mare, la terra i la llengua com a forces primigènies generadores de significats (Riba 20I2: 78-79).

Per a Maria Mercè Marçal, la seva expressió poètica, en clara recerca identitària, implicava el diàleg amb la tradició heretada, tan de la poesia culta com la popular:

Posar en qüestió uns arquetipus comporta entrar en conflicte amb una tradició. D'aquí que, necessitats com estem d'una col·lectivitat, la cerquem en una instància mítica que seria el popular. Per això Lorca és un poeta amb qui connecto tant. Ell acudí al popular perquè havia entrat en lluita amb la col-lectivitat real, històrica; en aquesta situació se cerca, no diré una pàtria perquè la paraula no m’agrada, però sí una comunitat. [...] Així et vincules a una tradició màgica, d'elements tan arrelats i ancestrals com ho poden ser el foc, l'aigua, l'aire... (Nadal I989: I86).

\section{Conclusions}

L'obra de Maria Mercè Marçal, des dels seus inicis, tal com ella mateixa va comentar en diverses entrevistes i altres textos assagístics, s'inscriu dins la tradició poètica internacional del neopopularisme. Un corrent ja present en la poesia catalana des de la Renaixença i força conreat abans i després de la Guerra per diferents

I2 En l'entrevista ja esmentada en el primer apartat ran de l'aparició del seu segon poemari, Bruixa de dol, Marçal explicava a Lluís Busquets i Grabulosa el seu intent d'unir la tradició literària catalana amb la veu de les que mai no havien tingut veu, les fades i les bruixes: «Com he dit en alguna banda, prossegueixo l'intent de trobar una veu pròpia que entronqui alhora amb la tradició literària catalana — com totes essencialment masculina_ i amb l'experiència quotidiana - sense veu- de les fades i les bruixes. Com a coses noves esmentaria una recerca molt més conscient de la meva veu com a dona, en el sentit individual i col-lectiu de la paraula. L'aparició del binomi bruixa-lluna, la dona solidària amb les altres dones i al mateix temps, com l'altra cara de la moneda, la dona sola: amb l'assumpció de la pròpia solitud com a condició indispensable per a l'existència com a individu autònom, com a "peix sense bicicleta"» (Busquets i Grabulosa 1989: 19-20). 
generacions. La poesia de Maria Mercè Marçal se serveix, dins d'aquest corrent, de formes i motius del folklore i de la literatura popular. En els seus poemes hi trobem formes populars, com corrandes, cançons, romanços, versos heptasíl.labs o repeticions de ritme i rima. Així com utilitza dites i refranys, o jocs infantils, endevinalles o festes populars, també se serveix d'altres figures i motius com, sobretot, les bruixes, amb una inversió simbòlica per aconseguir l'objectiu d'una escriptura pròpia i en femení.

Amb aquest objectiu concret, el metre i el contingut dels seus poemes tenen un fonament, són una tria conscient. Mitjançant la recreació de la tradició popular, Maria Mercè Marçal vol aconseguir una veu poètica, pròpia i personal. El punt de partida és vital i ve de la mare, qui li ha transmès una llengua viva, unes cançons, uns jocs i un imaginari de contes i llegendes. I és aquest món que l'apropa a les genealogies femenines, silenciades i subordinades. Així, aquestes formes i motius, amb d'altres elements, li permeten crear també, com deia García Lorca, del qual l'autora admetia la seva influència, una «comunitat».

Com García Lorca, Marçal apel·la també a la comunitat de la poesia popular perquè entra en lluita contra la col-lectivitat històrica. I la seva comunitat és la comunitat femenina i del feminisme, que li permet traçar una genealogia de filla de la mare,mare de la filla, germana - i alhora estrangera- de les altres dones, múltiples, bruixes i fades, però amb un propòsit comú: ser lliures. Un propòsit de reivindicació del seu cos i la seva sexualitat, i fer-ho amb la seva veu, cosificada i sexualitzada alhora. Una veu que, al mateix temps, ha de ser expressada dins d'aquest ordre de la mare en una tradició poètica, però dominada per l'ordre patriarcal que, a més, també ha dominat històricament el llenguatge. Coneixedora i seguidora de les escoles de teoria i crítica feministes franceses de la segona meitat del segle $\mathrm{xx}$, crea i recerca la seva «escriptura femenina».

Així, doncs, en la seva recerca d'aquesta veu pròpia de poeta amb cos de dona i de la recreació d'un univers també femení, Maria Mercè Marçal se serveix de la cultura apresa de la mare, la cultura popular. I ho fa tant amb formes mètriques de la literatura popular com de jocs i imaginari del món infantil i, sobretot, de figures com és el cas essencial de les bruixes, que li permeten configurar aquesta comunitat pròpia esmentada. I, si ella va reivindicar i recuperar les genealogies literàries femenines silenciades, la seva obra és també una baula i un referent, en bona part, de les poetes de les generacions posteriors. 
La utilització del folklore i la literatura popular per configurar l'ordre simbòlic...

\section{Referències bibliogràfiques}

AA. DD. (2008): Monogràfic «La poesia de Maria Mercè Marçal». Reduccions, núm. 89-90.

Alzueta, Miquel (I978): «M. Mercè Marçal, de classe baixa i nació oprimida». Mundo Diario (Barcelona, 6 de juliol de i978).

ARDERIU, Clementina (2008): Contraclaror. Antologia poètica. Barcelona: Horsori.

Broch, Àlex (2007): Sobre poesia catalana. Barcelona: Proa.

BARGALLó, Josep (2OI2): «Els sonets de Maria-Mercè Marçal: classicisme i modernitat». Disponible en línia: <https://josepbargallo.wordpress.com/20I2/03/25/ els-sonets-de-maria-merce-marcal-classicisme-i-modernitat/>[data de consulta: agost de 20I7].

BusqueTs, Lluís (I978): Entrevista «M. Mercè Marçal i Xavier Bru de Sala, dos poetes». El Correo Catalán (6 de maig de I978): I9-20.

Bordons, Glòria (2008): «Joan Brossa i Maria-Mercè Marçal». Dins Fina LlorCA; Heura MARÇAL (eds.): II Jornades marçalianes. Barcelona: Publicacions de l'Abadia de Montserrat, p. III-I3I.

CARBONELl, Neus (2004): «Feminisme i postestructuralisme». Dins Marta SEGARRA; Àngels CARABí (eds.): Feminismo y crítica literaria. Barcelona: Icaria.

Cixous, Hélène (I995): La risa de la medusa. Ensayos sobre la escritura. Barcelona: Anthropos.

CLIMENT, Laia (2002): «Filles i mares: la influència de la ginocrítica en els temes de filiació i maternitat en Llengua abolida de Maria-Mercè Marçal». Anuari de l'Agrupació Borrianenca de Cultura, XIII: 79-88.

- (2003): «Dones d'aigua. Dues visions femenines de la maternitat: Llengua abolida de Maria-Mercè Marçal i Et l'une ne bouge pas sans l'autre de Luce Irigaray». Dins Actes del Dotzè Col-loqui Internacional de Llengua i Literatura Catalanes. Barcelona: Publicacions de l'Abadia de Montserrat, volum II, p. 89-99.

— (2004): «Tradición y ruptura: el tratamiento de la literatura popular en Federico García Lorca y Maria Mercè Marçal». Dins Magdalena LEón (coord.): La literatura en la literatura: actas del XIV Simposio de la Sociedad Española de Literatura General y Comparada. Madrid: Ediciones de los Estudios Cervantinos, p. 335-345.

Corrons, Fabrice; Frayssinhes, Sandrine (eds.) (20I2): Lire / Llegir Maria-Mercè Marçal à propos de / sobre Bruixa de Dol. Perpinyà: Edicions Trabucaire.

DÍAZ, Noèlia (20I4): Constructing Feminine Poetics in the Works of a Late TwentiethCentury Catalan Woman Poet: Maria-Mercè Marçal. Cambridge: MHRA.

FERNÀNDEZ, Josep-Anton (2004): «Subversió, transició, tradició: política i subjectivitat a la primera poesia de Maria-Mercè Marçal». Lectora, núm. IO: 20I-2I6.

IbARZ, Mercè (2004) (ed.): Maria Mercè Marçal. Sota el signe del drac. Proses I985I997. Barcelona: Proa.

IRIGARAY, Luce (I974): Speculum de l'autre ferme. París: Éditions de Minuit.

- (I979): Et l'une ne bouge pas sans l'autre. París: Édicions de Minuit.

- (I985): Parler n'est jamais neutre. París: Éditions de Minuit.

Julià, Lluïsa (20I7): Maria Mercè Marçal. Una vida. Barcelona: Galàxia Gutenberg. 
López, Nunila; Myriam CAMEros (2004): La Cenicienta que no quería comer perdices. Barcelona: Planeta.

MARÇAL, Maria Mercè (I989): Llengua abolida (I973-I988). València: Tres i Quatre.

— (I996): «Elogi del drac». Ateneu, núm. 2i (juny de I996): I4-I5.

- (I997): «Dona i poesia: més enllà i més ençà del mirall de la Medussa». Dins Margarida AritzetA; Montserrat PALAu (eds.): Paraula de dona. Tarragona: Diputació de Tarragona, p. I75-I8I.

- (2004a): Cançó de saltar a corda. Il-lustracions de Judit MorALES. Barcelona: Cruilla.

— (2004b): La màgia de les paraules. Il-lustracions de Mabel PiérolA. Barcelona: Baula.

- (20I5): Tan petita i ja saps... Barcelona: Andana.

Montero, Anna (I995): «L'espai d'una llengua abolida». Dins L'escriptor del mes: Maria Mercè Marçal. Barcelona: Institució de les Lletres Catalanes, p. 9-Io.

- (2004): «Anna Montero entrevista a Maria Mercè Marçal». Lectora, núm. ıo: 259-283.

— (2008): «La triple lluna i el mirall. Cau de llunes i Bruixa de dol». Reduccions. Revista de Poesia, núm. 89-90: 230-240.

Muraro, Luisa (I995): El orden simbólico de la madre. Madrid: Horas y horas.

NADAL, Marta (I989): Entrevista «Els confins de la identitat». Serra d'Or, núm. 352 (març I989): I84-88.

OTERo, Mercè (2OIO): «La tradició popular i feminista en l'obra poètica de Maria-Mercè Marçal». Dins Fina LlorCA; Heura MARçAL (eds.): II Jornades marçalianes. Saba vella per a les fulles noves. Sabadell: Fundació Maria-Mercè Marçal, p. 7I-87.

PANÉ, Francesc (I977): Entrevista «Maria Mercè Marçal: un Carles Riba femení i transcendent». La Mañana (I2 de febrer de I977): II.

PONT, Jaume (I989): «Maria-Mercè Marçal. L'hora del mirall». Urc, núm. 4-5: 9I-93.

RiBA, Caterina (2OI2): «L'obra poètica de Maria-Mercè Marçal: una aproximació des dels estudis de gènere i la literatura comparada». Tesi doctoral dirigida per la Dra. Lluïsa Cotoner. Universitat de Vic. Disponible en línia: <http://repositori.uvic.cat/handle/I0854/I935> [data de consulta: agost de 20I7]

— (20I4): Maria Mercè Marçal. L'escriptura permeable. Vic: Eumo.

RomeU, Josep (1974): Poesia popular i literatura. Barcelona: Curial.

SABADELL, Joana (I998): "Allà on literatura i vida fan trena. Conversa amb Maria-Mercè Marçal sobre poesia i feminisme». Serra d'Or, núm. 467 (novembre I998): I2-2I.

SEgARrA, Marta (2004) (coord.): «Dossiers monogràfics. Maria Mercè Marçal». Lectora, núm. IO: 159-284.

SELfA, Moisés (2015): «La poesia infantil i juvenil de Maria Mercè Marçal». Mascançà. Revista d'Estudis del Pla d'Urgell, núm. 6: I75-I80.

SISTAC, Dolors (2000): «M. Mercè Marçal: tres baules». Dins Llengua abolida. Encontre de creadors. Lleida: Ajuntament de Lleida, p. III-II5. 